\title{
Beyond the Micro Level: A Value-Based Approach to Enhancing Personal Outcomes for Persons with Disabilities
}

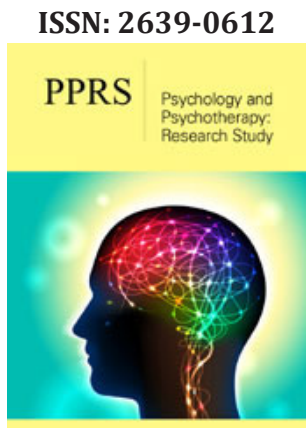

*Corresponding author: Claes C, Faculty of Psychology and Educational Sciences, Belgium

Submission: 毕 March 05, 2020

Published: 僵 March 18, 2020

Volume 3 - Issue 4

How to cite this article: Claes C, Lombardi M, Schalock R,Shogren K. Beyond the Micro Level: A Value-Based Approach to Enhancing Personal Outcomes for Persons with Disabilities. Psychol Psychother Res Stud. 3(4).PPRS.000570.2020.

DOI: 10.31031/PPRS.2020.03.000570

Copyright@ Claes C, This article is distributed under the terms of the Creative Commons Attribution 4.0 International License, which permits unrestricted use and redistribution provided that the original author and source are credited.

\section{Claes $\mathrm{C}^{1 *}$, Lombardi $\mathbf{M}^{2}$, Schalock $\mathbf{R} \mathrm{L}^{3}$ and Shogren $\mathrm{K}^{4}$}

${ }^{1}$ Hogent University of Applied Sciences and Art/Ghent University Belgium, Belgium

${ }^{2}$ Hogent University of Applied Sciences and Art/Ghent University Belgium, Belgium

${ }^{3}$ Hastings College, USA

${ }^{4}$ University of Kansas, USA

\begin{abstract}
In this paper, we argue for a value-based approach to enhancing personal outcomes for persons with a disability. Personal outcomes extend the psychological micro level. The rationale behind a value-based holistic approach is found in seven international movements that are influencing societal views and practices regarding persons with intellectual disability and related developmental disabilities (IDD). An explicit framework that goes beyond the psychological micro level in supporting people with a disability should come in place. In this paper, we argue for a value-based approach to enhancing personal outcomes for persons with a disability. In the field of disability, the concept of quality of life has evolved from a sensitizing notion to a measurable construct that includes eight domains and their respective indicators listed in Table 1. The QOL conceptual and measurement framework as summarized in Table 1 has been empirically validated across different cultures and countries [1-3]. In terms of personal outcomes, the concept of quality of life allows one to understand the context of human functioning and the potential of individuals to grow and develop across each of the eight domains summarized in Table 1.
\end{abstract}

Table 1: Quality of life conceptual and measurement framework.

\begin{tabular}{|c|c|c|}
\hline QOL Factor & QOL Domain & Exemplary QOL Indicators \\
\hline Independence & $\begin{array}{l}\text { Personal development } \\
\text { self-determination }\end{array}$ & $\begin{array}{l}\text { Education status, personal skills, } \\
\text { adaptive behavior, ADLs, IADLs } \\
\text { Choices/decisions, autonomy, } \\
\text { personal control, personal goals }\end{array}$ \\
\hline Social participation & Interpersonal relations & $\begin{array}{l}\text { Social networks, friendships, social } \\
\text { activities, relationships }\end{array}$ \\
\hline Social inclusion & $\begin{array}{l}\text { Community integration/ } \\
\text { participation,community } \\
\text { roles Rights }\end{array}$ & $\begin{array}{c}\text { Human (respect, dignity, equality),Legal } \\
\text { (legal access, due process) }\end{array}$ \\
\hline $\begin{array}{l}\text { Well-Being experiences, } \\
\text { contentment, self- } \\
\text { Concept, lack of stress }\end{array}$ & Emotional well-being & Safety and security, positive \\
\hline Material well-being & Physical well-being & $\begin{array}{c}\text { Health status, nutritional status, } \\
\text { recreation/physical exertion } \\
\text { Financial status, employment status, } \\
\text { housing status, possessions }\end{array}$ \\
\hline
\end{tabular}

\section{Introduction}

Personal outcomes extend the psychological micro level. We argue for a value-based holistic approach for which the rationale is found in seven international movements that are influencing societal views and practices regarding persons with intellectual disability and related developmental disabilities (IDD). First, there is the commitment to the human and legal rights of persons with disabilities reflected in the UNCRPD [4-7]. Second, the increasing 
adoption of the social-ecological model of disability has changed policy makers, service providers, and researchers understanding of the interaction between individuals and the multiple factors at the micro, meso, and macrosystem that affect human functioning and personal outcomes [8-11]. Third, the supports paradigm and the use of individualized support strategies that reduce the mismatch between a person's capabilities and the skills required by the environment for successful participation has become the primary emphasis in services/support delivery [12,13]. Fourth, the quality of life concept, with its emphasis on equity, inclusion, and empowerment and its focus on the quality of life domains of personal development, self-determination, social inclusion, interpersonal relations, and emotional, physical, and material well-being, is impacting both program development and outcome evaluation $[2,11]$.

Fifth, the capability approach to disability that emphasizes the core values of freedom and human dignity has resulted in an increasing emphasis on changing the conditions that a society creates to improve people's lives [14]. Sixth, positive psychology has shifted the field from a focus on defect ology to an emphasis on optimal human functioning and well-being and practices based on virtues and strengths, happiness and positive emotional well-being, positive development, a life worth living, thriving and flourishing, and resilience $[15,16]$. Finally, changes in the field of IDD have impacted how personal support plans are developed and implemented. Chief among these changes are a focus on the person and their rights, systems thinking and logic models, systems of support, information technology, support teams, outcome evaluation, and evidence-based practices [12].

The values underlying the value-based approach to enhancing personal outcomes include: (a) the potential for all persons to grow, develop, and contribute to their society; (b) the human and legal rights of people to live in least restrictive and safe environments, to participate fully in their communities, and to be contributing members of their society; (c) a person's disability cannot be viewed in isolation, but rather as the result of an interaction between the person's capability and their environment's demands; (d) with appropriate supports over time, human functioning can be enhanced; and (e) the desire for a life of quality among all persons. These values can be used as a basis for both personal support plan development and for creating societal conditions that allow for developing a person's capacities and improving peoples' lives. As described by Nussbaum [14], Cox et al. [17], De Maeyer et al. [18] and Sen [19] these societal conditions are based on human dignity and involve political liberty, economic freedom, social opportunities, protection and security, and advocacy. Furthermore, the conditions emphasize social justice, quality of life, the freedom to achieve a life that one has reason to value, and enhanced human functioning [20]. An explicit framework that goes beyond the psychological micro level in supporting people with a disability should come in place [21,22].

\section{Conclusion}

The purpose of this article was to describe a value-based approach to enhance personal outcomes for persons with disabilities. The essential components of a value based approach: (a) focus on the role that capabilities opportunities and liberties play in the enhancement of an individual's QOL; and (b) encompass a quality improvement cycle involving policies and practices that lead to personal outcomes and consider context. Due to the complexity of the process, we suggest considerations for its implementation rather than a group of specific guidelines.

\section{References}

1. Jenaro C, Verdugo MA, Caballo C, Balboni G, Lachapelle Y, et al. (2005) Cross-cultural study of person-centred quality of life domains and indicators: a replication. J Intellect Disabil Res 49(10): 734-739.

2. Schalock RL, Verdugo MA (2002) Handbook on quality of life for human service practitioners. American Association on Mental Retardation. Washington, USA.

3. Schalock RL, Verdugo MA, Jenaro C, Wang M, Wehmeyer M, et al. (2005) Cross-cultural study of quality of life indicators. Am J Ment Retard 110(4): 298-311.

4. Karr VL (2011) A life of quality: Informing the UN convention on the rights of persons with disabilities. Journal of disability policy studies 22(2): 67-82.

5. Shogren KA, Wehmeyer ML, Singh NN (2017) Handbook of positive psychology in intellectual and developmental disabilities. Springer, Berlin, Germany.

6. Mittler P (2015) The UN convention on the rights of persons with disabilities: Implementing a paradigm shift. Journal of Policy and Practice in Intellectual Disabilities 12(2): 79-89.

7. United Nations (2006) Convention on the rights of persons with disabilities.

8. Abbott S, McConkey R (2006) The barriers to social inclusion as perceived by people with intellectual disabilities. J Intellect Disabil 10(3): 275-287.

9. Claes C, Van Hove G, Vandevelde S, Van Loon J, Schalock R (2012) The influence of supports strategies, environmental factors, and client characteristics on quality of life-related personal outcomes. Res Dev Disabil 33(1): 96-103.

10. Schalock RL, Verdugo MA, Gomez LE (2011) Evidence-based practices in the field of intellectual and developmental disabilities: An international consensus approach. Eval Program Plann 34(3): 273-282.

11. Schalock RL, Verdugo MA (2012) A Leadership guide for today's disabilities organizations: overcoming challenges and making change happen. Brookes Publishing Company. Baltimore, USA.

12. Schalock RL, Thompson JR, Tasse MJ (2018b) Changes in the field regarding personal support plans. AAIDD, Washington, USA.

13. Thompson JR, Schalock RL, Agosta J, Teninty L, Fortune J (2014) How the supports paradigm is transforming the developmental disabilities service system. Inclusion 2(2): 86-99.

14. Nussbaum MC (2011) Creating capabilities. Harvard University Press, USA.

15. Shogren KA, Turnbull HR (2014) Core concepts of disability policy, the convention on the rights of persons with disabilities, and public policy research with respect to developmental disabilities. Journal of Policy and Practice in Intellectual Disabilities 11(1): 19-26. 
16. Wehmeyer ML, Shogren KA (2016) Positive psychology and a qualityof-life agenda. In Cross-cultural quality of life: Enhancing the lives of people with intellectual disability. In: Schalock RL, Keith K (Eds.), AAIDD, Washington DC, USA, pp. 143-148.

17. Cox D, Pawar M, Pawar MS (2006) International social work: Issues, strategies, and programs. Sage Publications, USA.

18. De Maeyer J, Vandenbussche H, Claes C, Reynaert D (2017) Human rights, the capability approach and quality of life: An integrated paradigm of support in the quest for social justice. Therapeutic Communities: The International Journal of Therapeutic Communities.

19. Sen AK (1999) Development as Freedom. Oxford University Press, UK.
20. Sacchetto B, Ornelas J, Calheiros MM, Shinn M (2018) Adaptation of Nussbaum's capabilities framework to community mental health: a consumer-based capabilities measure. Am J Community Psychol 61(12): $32-46$.

21. Claes C, Van Hove G, Van Loon J, Vandevelde S, Schalock RL (2010) Quality of life measurement in the field of intellectual disabilities: Eight principles for assessing quality of life-related personal outcomes. Social Indicators Research 98(1): 61-72.

22. Schalock RL, Keith KD (2016) Cross-cultural quality of life: Enhancing the lives of people with intellectual disability. Aaidd, USA.

For possible submissions Click below:

Submit Article 